\title{
A ARTE DE FABRICAR MOTINS: OS MARCOS REGULATÓRIOS DA MINERAÇÃO DIAMANTÍFERA EM PERSPECTIVA HISTÓRICA
}

\author{
Marcos Lobato Martins ${ }^{1}$
}

\begin{abstract}
Resumo
$\mathrm{O}$ artigo, apoiado na historiografia existente e fontes locais (depoimentos de garimpeiros e jornais diamantinenses), discute as alterações do arcabouço legal que regia a mineração no Brasil, enfatizando a situação dos garimpeiros de diamantes na região do Alto Jequitinhonha, Minas Gerais. São abordadas as relações entre garimpeiros, donos de terras, empresas mineradoras e governo, com o objetivo de mostrar as contradições entre eles e as dificuldades postas pela legislação para o desenvolvimento do garimpo.
\end{abstract}

Palavras-chave: legislação minerária, garimpo, diamante, Minas Gerais.

\begin{abstract}
This paper, supported in historical production and local sources (newspapers and prospectors testimonies), examines the changes of brazilian's mining legislation, emphasizing the diamond prospectors situation in Upper Jequitinhonha region, Minas Gerais. It approaches the relations between prospectors, land proprietaries, mining enterprises and governments, with the intent to exhibit the contradictions between them and difficulties in the mining development caused by legislation.
\end{abstract}

Key words: mining legislation, prospecting, diamond, Minas Gerais.

A mineração é atividade destacada na economia brasileira desde o início do século XVIII, respondendo, em boa medida, pelo processo de expansão territorial e pela fixação de contingentes populacionais no interior. Regiões como Minas Gerais, Goiás, Mato Grosso e Bahia constituem espaços tradicionais de atividades minerárias, às quais se juntaram, principalmente a partir de meados do século passado, vastas porções da Amazônia Legal. No caso dos minerais de maior valor por unidade de volume, caso do ouro e das pedras preciosas, aos quais se pode juntar a cassiterita, a garimpagem sempre respondeu por boa parte da produção e conviveu com a grande empresa mineradora. Convivência marcada por momentos ora de cooperação, ora de franca hostilidade, com durações e intensidades variáveis.

Os dados disponíveis sobre o garimpo são eloqüentes. Conforme o Levantamento Nacional dos Garimpeiros (LNG), realizado pelo DNPM (Departamento Nacional da Produção Mineral) em 1991, e publicado em 1993, havia 291.727 garimpeiros ativos no território nacional, 61\% deles no Norte do país. O próprio DNPM considerou que seria mais realista estimar em $400 \mathrm{mil}$ o total de homens vinculados diretamente ao garimpo de ouro, diamantes e pedras coradas. Esse exército de garimpeiros respondia, no ano de 1991, por $94 \%$ da produção de diamante e $44 \%$ da produção de ouro. Nas catas de áreas garimpeiras tradicionais ou nas frentes de lavras da Amazônia, eles trabalhavam, em média, 40 a 50 horas semanais, obtendo rendimento médio nacional per capita de 3,8 salários mínimos mensais (DNPM, 1993). Na região de Diamantina, estimava-se que, no ano de 2001, atuavam 30 mil pessoas nas catas de diamante, trabalhando intensamente no período da estiagem, de 5 a 6 meses por ano. Os garimpeiros de Diamantina receberiam, conforme estimativas da época, renda média mensal de 2,5 salários mínimos.

A despeito de sua inegável relevância econômica, histórica e cultural, o garimpo enfrenta, nas últimas décadas, conjuntura difícil. A atividade - e seus praticantes - adquiriu imagem bastante negativa, tornando-se ícone do "Brasil atrasado, pobre e violento" que se deseja superar por meio da modernização capitalista ${ }^{2}$. A crescente preocupação com as temáticas ambientais carreia tintas ainda mais pesadas para essa imagem do garimpeiro, a ponto de, recentemente, a poderosa Vale do Rio Doce veicular na mídia nacional propaganda que dizia: "A Vale não faz garimpo. A Vale faz mineração”. Justamente ela, que mantém relações promíscuas com garimpeiros no sul do Pará...

Esta situação delicada do garimpo frente à opinião pública tem muitas explicações. Todavia, não há dúvida de que a legislação minerária, desde os tempos coloniais, é um dos fatores mais decisivos. Isso porque sempre marginalizou a atividade garimpeira, colocando os garimpeiros na clandestinidade e no limiar da criminalidade. Simultaneamente, alimentou padrão esquizofrênico de relações entre o garimpo e a empresa mineradora, favorecendo a multiplicação de conflitos pelas terras minerais. O objetivo deste

\footnotetext{
1 - Trabalho apresentado no VIII Encontro Regional Gestão \& Tecnologia, realizado pelas Faculdades Pedro Leopoldo de 22 a 25 de outubro de 2008, no Simpósio sobre Políticas Públicas e Sistemas de Informação.

Coordenação do Prof. Dr. Luis Aureliano Gama de Andrade.

2 - Sobre as imagens do garimpo e dos garimpeiros na história brasileira, ver Marcos Lobato Martins (1997).
} 
trabalho é analisar, numa abordagem histórica, os marcos regulatórios da mineração de diamantes no país, enfatizando, por um lado, o tratamento conferido, nos diversos períodos, para a atividade garimpeira e, por outro lado, os problemas que a legislação colocou para o desenvolvimento da mineração diamantífera. A discussão concentra-se num estudo de caso, atendo-se a mais antiga e famosa área diamantífera brasileira: o entorno de Diamantina, no Alto Vale do Jequitinhonha, nordeste de Minas Gerais.

\section{O ARCABOUÇO REGULATÓRIO NO PERÍODO COLONIAL}

A descoberta de ricas jazidas de diamantes na Comarca do Serro Frio, no entorno do antigo Tijuco, na década de 1720 , forçou as autoridades portuguesas a montarem, rapidamente, aparato de controle e fiscalização da mineração dessas gemas. A primeira razão da urgência é a sensibilidade do preço do diamante às variações da oferta - era preciso evitar que as pedras do Tijuco inundassem os mercados europeus. A segunda razão era fiscal: combater o contrabando e reduzir ao máximo a sonegação de impostos.

Em 1730, foi criado o Regimento sobre os diamantes, documento que juntou ao Regimento das Minas de 1720. Por esse diploma legal, institui-se que o diamante era propriedade real. Depois de breve período de livre exploração das lavras, a Coroa optou pelo regime de monopólio da extração diamantífera. Primeiro, com os contratos, que vigoraram entre 1739 e 1771. Depois com o monopólio régio, consubstanciado na criação da Real Extração (1771-1832).

O sistema de contratos baseava-se no arrendamento do direito de exploração diamantífera a terceiros, por meio da realização periódica de hastas públicas, levadas a efeito na Vila do Príncipe (atual cidade do Serro). $\mathrm{O}$ indivíduo ou sociedade de indivíduos vencedor da hasta, que se tornava "contratador", obrigava-se a pagar, anualmente, royalties no valor de 138 contos de réis, além do imposto de captação sobre cada escravo empregado nas lavras (valor anual de $230 \mathrm{mil}$ réis). Os contratadores podiam empregar, no máximo, 600 escravos nas catas. Sobre os diamantes obtidos, incidia o imposto do quinto. As pedras só podiam ser transportadas para a Europa em naus portuguesas, incidindo sobre elas frete na proporção de $1 \%$ sobre o valor de cada uma. Para controlar e fiscalizar a atuação dos contratadores, foi criada a Intendência dos Diamantes, com numeroso séquito de "oficiais".

O regime de contratos proibiu o garimpo, isto é, toda mineração de ouro e diamante no Distrito Diamantino realizada por outra pessoa que não o contratador ${ }^{3}$. Sem meias palavras, os garimpeiros eram considerados forada-lei, perseguidos sem trégua e aprisionados. Essa era a lei. Entretanto, como ilustra o caso do Contratador Felisberto Caldeira Brant (1748-1751), a praxe era deixar os garimpeiros trabalharem e, em seguida, tomarlhes à força os "descobertos". Havia, pois, relações informais entre os garimpeiros e os contratadores - os primeiros abriam caminho para as tropas de escravos dos segundos. Conluio feito em nome da prosperidade da mineração, sob a vista grossa das autoridades assentadas no Tijuco, no Serro e em Vila Rica.

O Marquês de Pombal, que considerou estar fora de controle o contrabando nas lavras do Distrito Diamantino, decidiu, em 1771, mudar o regime de exploração. Foi então implantada a Real Extração de Diamantes, cuja operação tinha por base o Livro da Capa Verde, isto é, o Regimento Diamantino publicado nesse mesmo ano. Segundo a historiografia tradicional, a Real Extração transformou o Distrito Diamantino num "estado dentro do estado", tais eram os rigores impostos pelo Livro da Capa Verde, que deram origem a uma administração local diferenciada e diretamente subordinada à Coroa ${ }^{4}$. Além da antiga Intendência dos Diamantinos, cujos poderes foram reforçados, criou-se a Administração Diamantina. Cada um desses órgãos com sua guarda, incumbidas de executar política repressora dentro do Distrito Diamantino. Havia também uma "esquadra de pedestres", tropa de infantaria de segunda linha, composta por mestiços, cuja tarefa era percorrer a região à caça de garimpeiros, retornando ao Tijuco a cada mês.

Portanto, uma dispendiosa e corrupta estrutura de controle da mineração de diamante caracterizou os tempos coloniais no Arraial do Tijuco. Feitores, soldados, escrivães, meirinhos, intendentes, ouvidores. Quartéis e registros nas estradas ${ }^{5}$. As negociatas envolvendo os "oficiais" integrantes dessa estrutura e habitantes do Distrito Diamantino eram comuns, freqüentemente ilegais e escandalosos. Privilégios e propinas, abusos de poder e interpretações arrevesadas da lei corriam soltos, favorecendo, é claro, as camadas bem situadas da sociedade regional. A economia sofria, e as rendas da Coroa diminuíam. Mais havia algo ainda mais nocivo, capaz de perturbar a cena regional nos tempos coloniais. Trata-se da grande quantidade de conflitos de jurisdição entre as autoridades. As competências dos cargos eram definidas com imprecisão, gerando superposições, áreas de indefinição. Isso só fazia multiplicar os abusos de autoridades, as disputas renhidas entre ouvidores, intendentes, contratadores, governadores, juízes de fora, etc. Caldo de cultura para os potentados, que praticamente se arvoraram régulos $^{6}$. Assim, redes de apadrinhamento cresciam

\footnotetext{
3 - Em 1731, a Coroa demarcou o Distrito Diamantino, procurando dificultar o acesso às lavras, por meio de proibições de entrada e da cobrança de altíssimas taxas de captação. Tendo o Tijuco por centro, o Distrito era um quadrilátero delimitado pelos registros de Caeté-Mirim, Rabelo, Palheiro, Pé do Morro, Inhacica e Paraúna.

4 - Para uma crítica contundente desse ponto de vista, ver Junia Ferreira Furtado (1996).

5 - Registros eram postos de fiscalizações em pontos estratégicos dos caminhos, onde eram cobrados impostos sobre mercadorias, direitos de entradas e de passagem dos rios e fiscalizados os viajantes.
} 
como estratégia de sobrevivência entre os habitantes do Distrito Diamantino, sem o que não se podia "ficar a salvo da lei” nem obter um quinhão nos negócios em torno da mineração.

Nesse ponto, é preciso concordar com Joaquim Felício dos Santos, o senador republicano de Diamantina: perderam o povo simples, especialmente os faiscadores e pequenos mineradores, e a economia regional, pois a exploração das lavras ficava aquém do potencial regional. A prova disso teria sido, ainda conforme Joaquim Felício dos Santos (1976), o boom minerador que se seguiu à extinção da Real Extração, que transformou Diamantina na "capital do Norte mineiro".

\section{CONTROLE E FISCALIZAÇÃO DA MINERAÇÃO DE DIAMANTES NO IMPÉRIO}

A Independência do Brasil, ocorrida num quadro internacional de ascensão da ideologia liberal e do avanço da hegemonia inglesa sobre o planeta, particularmente a América do Sul, produziu mudança substancial na legislação minerária. Ao invés do monopólio da exploração das lavras de diamante, era a vez do regime de livre exploração, franqueado inclusive aos estrangeiros. Por isso, Minas Gerais, já na década de 1830, recebeu companhias inglesas de mineração aurífera, destacando a Saint John D'el Rey Mining Company, instalada em Morro Velho (município de Nova Lima).

A Constituição de 1824 adotou o regime dominial, pelo qual os minérios eram considerados propriedade do Estado. O controle das lavras e dos mineradores passou a ser responsabilidade das Províncias. Para os diamantes, restou a obrigação de lapidar as pedras no Rio de Janeiro, nas dependências da "Fábrica de Lapidação" do Tesouro Nacional. Havia, porém, uma dificuldade na Constituição de 1824 , que não foi efetivamente sanada por leis ordinárias posteriores. Não ficara bem definida a separação da propriedade do solo e do direito de explorar as riquezas minerais.

Esta indefinição teve o efeito de acirrar as disputas entre os proprietários dos "lotes de terras minerais" e os mineradores (ou garimpeiros). Os grandes mineradores cuidaram de regularizar as terras que compraram, muitas vezes sem pressa para lavrá-las. Ficavam à espera de boas ofertas de compra das companhias nacionais e estrangeiras ou de outros mineradores. A especulação com os terrenos diamantinos cresceu no decurso do período. Enquanto isso, os garimpeiros - que já não eram mais criminosos, em função do regime de livre exploração - ficaram diante da escassez de áreas para trabalhar. Na região de Diamantina, os conflitos entre garimpeiros e proprietários de terrenos diamantíferos adquiriram intensidade. Os mais agudos talvez tenham sido os conflitos de Curralinho (1861), Rio das Pedras (1861), São João da Chapada (1863) e Pau de Fruta (1873), sempre resolvidos em favor dos proprietários pela diligente e impiedosa ação da Guarda Nacional. Esses conflitos revelam, também, que permanecia a sina da Colônia: os garimpeiros faziam os grandes "descobertos" e, então, eram expulsos pelos grandes mineradores e diamantários (negociantes de ouro e diamantes), os proprietários legais dos "terrenos minerais".

A peça-chave da engrenagem era a Repartição dos Terrenos Diamantinos, órgão criado por volta de 1860 e vinculado à Secretaria de Agricultura, Comércio e Obras Públicas de Minas Gerais. Esse órgão cuidava do registro das áreas das jazidas e das concessões e autorizações para lavra. Instalado em Diamantina, foi ferreamente capturado e dirigido pelas elites diamantinenses, cujo poder político nos tempos imperiais era bastante considerável. Na verdade, os interesses dos grandes mineradores e diamantários do antigo Tijuco privatizaram - esse é o termo justo - a referida Repartição. Dessa forma, na segunda metade do século XIX ocorreu forte processo de concentração dos terrenos minerais. Para milhares de homens que viviam da cata de diamantes, não restou outra saída senão integrar as "turmas" dos poderosos donos de lavras, trabalhando no sistema de $\operatorname{praças}^{7}$. Os poucos que não se submeteram tornaram-se faiscadores, mineradores isolados que tentam serviços modestíssimos nos córregos mais afastados e, em geral, pouco promissores. Novamente, portanto, os garimpeiros foram empurrados para o lusco-fusco da marginalidade econômica e social.

As falhas da legislação imperial concernente à mineração, a concentração dos terrenos diamantinos nas mãos de poucos mineradores e diamantários, a especulação nos negócios de compra e venda das áreas de lavra, a desordem dos registros da Repartição dos Terrenos Diamantinos, tudo isso elevou os custos de transação para as companhias que se interessaram pelo Alto Jequitinhonha. É provável que muitas firmas, constituídas no Rio de Janeiro ou no estrangeiro, tenham desistido de operar na região de Diamantina.

\section{O MARCO REGULATÓRIO NA PRIMEIRA REPÚBLICA}

A Proclamação da República provocou alteração na legislação minerária. A Constituição de 1891, que manteve o controle do setor de mineração nas mãos dos Estados, optou pelo regime do direito fundiário. O que significa que as jazidas eram consideradas pertencentes aos proprietários dos solos.

\footnotetext{
${ }^{6}$ - A relação entre a desorganização político-administrativa e a fragilidade da ordem pública é trabalhada por Carla M. Junho Anastasia (2005).

7 - Praça é o nome dado ao trabalhador da mineração de diamantes que trabalho por uma porcentagem pequena do lucro apurado na cata. O dono da lavra garante a ele alimentação, ferramentas e habitação (ranchos precários, de madeira e sapé, no local do serviço).
} 
Ora, esta opção teve o poder de trazer mais um ator para as tramas dos conflitos na mineração de diamantes no Alto Jequitinhonha, como de resto no país inteiro. Além do garimpeiro, pressionado pela escassez de áreas realmente livres para trabalhar, entrou para o ringue o dono do solo, o chamado "dono-da-serra". Pelo simples fato de ser o proprietário legal da área, o "dono-da-serra" passou a ter a palavra final sobre o serviço de lavra. Se quisesse, impedia o intento do minerador. Para aquiescer, entretanto, descobriu logo que tinha a chance de exigir uma "parte gorda" nos lucros do empreendimento minerador. Sem fazer nada, deixando toda a labuta e toda a despesa correrem por conta do minerador. O olho grande do "dono-da-serra" avançou sobre a lucratividade do minerador.

A gritaria dos mineradores não demorou a chegar aos ouvidos do governo. Em 1915, a Lei Pandiá Calógeras e, em 1921, a Lei Simão Lopes tentaram apaziguar os ânimos, sem muito sucesso. Na prática, elas concederam alguns direitos aos prospectores responsáveis pelas descobertas das jazidas. Enquanto proprietários de terras e mineradores lutaram por seus interesses, na medida em que debatiam as leis de mineração na República dos Fazendeiros, os garimpeiros continuaram esquecidos pelos ocupantes dos palácios da Capital Federal.

Fator adicional de tensão no Nordeste de Minas Gerais foi a desconfiança das elites diamantinenses de que, secretamente, o governo do estado alimentava a intenção de transferir, para Belo Horizonte, a Repartição dos Terrenos Diamantinos. Essa desconfiança, que atravessou todo o período, envenenava as relações políticas entre Diamantina e o Palácio da Liberdade. Perder o controle sobre a burocracia encarregada de controlar e fiscalizar as atividades de extração de diamante seria golpe duro demais. Por isso, quando, na virada de 1903 para 1904, correram na cidade boatos de que o governo ordenara a transferência da Repartição para Belo Horizonte e a mudança de status do órgão dentro da Secretaria de Agricultura, Diamantina entrou em convulsão. As elites locais mobilizaram o povo, organizaram marchas e comícios, pressionaram a Câmara Municipal. A sede da Repartição dos Terrenos Diamantinos foi invadida, os seus arquivos foram seqüestrados, sob o olhar cúmplice do Delegado de Polícia, do Comandante do 30 Batalhão da Força Pública de Minas Gerais e do Juiz de Direito da Comarca.

\footnotetext{
O jornal diamantinense O Itambé descreveu o movimento nos seguintes termos:

Durante a manhã do dia 26, a população veio para a rua comentando os fatos, na maior exaltação contra o governo. Às três horas da tarde, como por encanto, organizou-se, no largo da Sé, um meeting popular, com música e fogos, para protestar contra a atitude do governo em relação aos terrenos diamantinos. Em menos de dez minutos, mais de 600 pessoas estavam reunidas na praça.
}

(...) E a massa popular rolou como uma avalanche, pela rua do Amparo abaixo, engrossando a cada passo, entre exclamações exaltadas. 'Morra o governo que nos quer espoliar da nossa propriedade em proveito próprio!' - diziam uns. (...) E ainda: 'Viva a independência de Diamantina!' 'Viva a soberania do povo!' Ao aproximar-se da Coletoria, a multidão se compunha de cerca de 2500 pessoas. A Coletoria foi invadida, o coletor dominado. Todos os livros e papéis do arquivo dos terrenos diamantinos colocados dentro de dois baús, fechados a chave, lacrados e entregues a uma comissão popular, que ficou como depositária. $\mathrm{O}$ arquivo passou pela multidão, entre aclamações (...). A massa popular saiu a percorrer as ruas, falando ainda diversos oradores, e dissolveu-se (O Itambé, ano 3, n. 103, p. 1, 1904. Gaveta 6, maço 32. Biblioteca Antônio Torres. IPHANDiamantina).

Diante do motim dos diamantinenses, o Palácio da Liberdade tratou de serenar os ânimos, jurando que nunca cogitara de tirar da cidade a sede da Repartição. O que, de fato, só viria a ocorrer na Era Vargas.

\section{O CÓDIGO DE MINAS DE 1934 E OS SERVIÇOS DE LAVRA EM DIAMANTINA ${ }^{8}$}

A ascensão de Getúlio Vargas ao poder, na chamada Revolução de 1930, iniciou tempo de modernização das estruturas econômicas e do aparato estatal brasileiro. Industrialização, centralização política, trabalhismo, intervenção estatal na economia. Estavam terminados os decênios de predomínio absoluto dos grandes proprietários rurais.

O setor da mineração tornou-se estratégico, inclusive porque cresceu a influência do Exército na política brasileira. Era preciso deslanchar, em bases modernas, a extração de ferro, manganês, calcário. Aproveitar melhor as águas minerais, as areias monazíticas. Também convinha pensar no petróleo. O que não se faria sem nova legislação minerária. Por isso, a Lei n. 24.642 foi aprovada dias após a promulgação da Constituição de 1934.

Esta Lei, que ficou conhecida como Código de Minas de 1934, estabeleceu a separação entre a propriedade territorial e a mineral "para efeito de exploração ou aproveitamento industrial". A União reservou-se competência exclusiva para legislar sobre mineração.As atividades mineradoras passaram ao regime de autorização ou concessão federal, permitidas apenas a brasileiros ou empresas organizadas no Brasil. A ênfase do Código de Minas era colocada sobre os grandes projetos de mineração. Mas havia referência ao garimpo. O novo diploma reconhecia certo valor para o garimpo em regiões do país, e também previa a permissão de livre garimpagem nas terras devolutas e nos rios. O Decreto-Lei n. 466, de junho de 1938, delimitou zonas de garimpagem no Brasil, que seriam áreas nas quais a explotação dos recursos minerais estaria reservada aos processos tradicionais do garimpo.

\footnotetext{
8 - Daqui em diante, as referências sobre legislação minerária são baseadas em Catharino (1986).
} 
Seria o Decreto-Lei 466 a redenção tão ansiada pelas comunidades garimpeiras espalhadas pelo Brasil? Não realmente. $\mathrm{O}$ motivo da frustração das expectativas residia num canto do Código de Minas de 1934. O DNPM, órgão criado em 1934, era o responsável pelos processos de "autorização de pesquisa ou concessão de lavra", que pessoas e empresas deveriam obter para atuar legalmente no setor. Não havia limite para o número dessas solicitações que uma pessoa ou empresa podia requerer. Mas, uma área sobre a qual houvesse autorização de pesquisa ou concessão de lavra tornava-se vedada para garimpo, faiscação ou cata. A garimpagem em área sem concessionário de pesquisa ou lavra implicava na obrigação do garimpeiro entregar o quinto - o antigo imposto reinol - para ao "dono-da-serra"

Na prática, esses dispositivos do Código de Minas de 1934 garantiram a continuidade da concentração dos direitos minerários e sua manipulação especulativa. Muita gente sentava em cima dos alvarás de pesquisa e das concessões de lavra, tornando-se "sócio parasitário" de garimpeiros e empresas mineradoras. Por outro lado, vale lembrar que Vargas também não estendeu ao garimpeiro os benefícios da legislação trabalhista.

Assim, o Código de Minas de 1934 oferecia algo aos garimpeiros com uma mão, para imediatamente retirar com a outra. A sina da marginalidade econômica e social prosseguia, no governo do "Pai dos pobres". Para as empresas, sobretudo as grandes, a situação era outra: apoio, estímulo, proteção. Pode-se apenas fazer o reparo, a la Eugênio Gudim, de que o tom francamente nacionalista do Código de Minas de 1934 embaraçava o desenvolvimento do setor minerador, por causa da aversão à participação do capital estrangeiro.

O período sob a égide da Constituição de 1946 não trouxe alteração significativa para a legislação minerária. O DNPM cresceu e, no caso do ouro, diamante e pedras coradas, cuja produção seguia dominada pelos garimpeiros, enredou-se em arranjos corruptos com os donos de alvarás de pesquisa ou concessões de lavras "de gaveta".

\section{O PERÍODO MILITAR: O QUE IMPORTA É EXPORTAR MINÉRIOS}

Os governos militares, que administraram o Brasil entre 1964 e 1985, voltaram atenção maior para o setor mineral, cuidando ainda mais dos grandes projetos e da orientação exportadora. Em janeiro de 1967, entrou em vigor o Código de Mineração, que conservava muitos elementos do Código de Minas de 1934. Inclusive a situação de excesso cartorial.

No que tange ao garimpo, o Código de Mineração implantou o regime de matrícula. Garimpeiros e faiscadores deveriam fazer registro específico na Exatoria Federal no local da cata. A "carteira de garimpeiro" dava o direito à pessoa trabalhar legalmente. Do ponto de vista trabalhista, o garimpeiro foi considerado um tipo de trabalhador rural.
Foi mantida pelo Código de Mineração a exigência da autorização de pesquisa e da concessão de lavra como requisitos de acesso legal às jazidas, documentos que continuaram a ser expedidos pelo DNPM. Dessa forma, a escassez de áreas para o trabalho sossegado dos garimpeiros não foi resolvida. Até porque as autorizações de pesquisa e as concessões de lavra não tinham prazos de validade estipulados pelo Código de Mineração. Elas significaram "reservas de áreas" praticamente duradouras, mesmo para pessoas e empresas que nenhum trabalho iniciaram nessas áreas.

Para suavizar o problema, o Código de Mineração deixava aberta a possibilidade de, a qualquer tempo, o governo delimitar "zonas de garimpagem". A competência para tal era do Ministro de Minas e Energia, a partir de propostas encaminhadas pelo DNPM. Esse dispositivo virou letra morta. E o que é pior, o Decreto-Lei n. 1.038, de outubro de 1969, revogou as zonas de garimpagem demarcadas na época do Estado Novo.

Outra vez, o que o Governo Federal dava para o garimpeiro com uma mão, retirava com a outra.

$\mathrm{Na}$ região de Diamantina, o quadro dos direitos minerários continuou dominado pela desorganização e pelo bloqueio de imensas áreas. É o que sugere a tabela abaixo, cujos dados incluem os títulos referentes à exploração de diversos recursos além do diamante:

Como, na experiência regional, a grande maioria dos interessados em Alvarás de pesquisa e concessões de lavra quer tão-somente arrendar aos garimpeiros ou negociar com empresas mineradoras, havendo também os que pretendem simplesmente bloquear o acesso nas suas propriedades, percebe-se que os garimpeiros não tiveram alternativa: tocaram suas catas na ilegalidade. Até as grandes empresas que almejassem iniciar projetos de extração de ouro e diamantes na região encontrariam dificuldades para obter áreas onde pudessem trabalhar.

\section{OS MARCOS REGULATÓRIOS DA NOVA REPÚBLICA}

A Constituição de 1988 iniciou mais um processo de reorganização da atividade mineradora. O Artigo 176 delineia os preceitos para o setor, a saber: a) as jazidas pertencem à União, cabendo-lhe conceder autorizações ou concessões; b) a propriedade do solo é distinta da propriedade dos recursos minerais para efeito de exploração ou aproveitamento; c) a garantia ao concessionário da jazida da propriedade do produto da lavra; d) a mineração é atividade restrita a brasileiros ou empresas brasileiras de capital nacional e; e) as autorizações de pesquisa têm prazo determinado, e tanto elas quanto as concessões podem ser cedidas ou transferidas sem prévia anuência do Estado.

A Constituição de 1988 também estabeleceu compensações financeiras para os municípios e estados 
TABELA 1

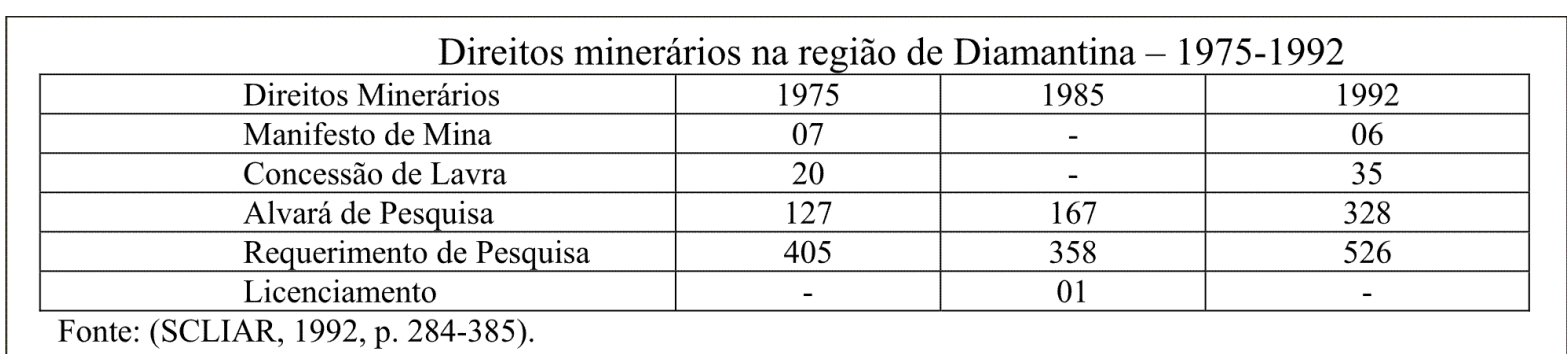

mineradores (royalties). No Artigo 43 das Disposições Transitórias, ficou decidido que, no prazo de um ano após a promulgação, os títulos de direitos minerários inativos ficariam sem efeito. Mas o novo Código de Mineração, que deverá regulamentar os artigos da Constituição que referentes à atividade mineradora, ainda não foi votado. O Código de 1967 permanece, portanto, em vigor. Como nele existem diversos tópicos em contradição ao estipulado na Carta Magna de 1988, o DNPM viu-se forçado a legislar por intermédio de Portarias. A confusão no marco legal da mineração continua. E uma grande dificuldade para o exercício pleno da soberania da União sobre os recursos minerais continuou sendo a não definição de prazo para a concessão de lavra.

Relativamente ao garimpo, a Lei Federal n. 7.805, de julho de 1989, criou o regime de permissão de lavra garimpeira, inspirado no exemplo das reservas extrativistas do Acre. Como na proposta tornada famosa pelo líder seringalista Chico Mendes, nascia a "reserva garimpeira": área destinada ao aproveitamento imediato de jazida garimpável, sem exigência de trabalhos prévios de pesquisa. No plano normativo, ocorreu, portanto, o reconhecimento do garimpo como atividade tradicional e sinalizou-se a direção para sua plena legalização: a formação de cooperativas de garimpeiros dentro das reservas garimpeiras. Outro fato marcante foi a publicação, em março de 1992, da Portaria n. 2. Esta portaria do DNPM delimitou como área de garimpagem um enorme território, de 1.178 .375 hectares, nos municípios de Diamantina, Monjolos, Gouveia, Datas e Bocaiúva.

Todavia, nem o DNPM nem as associações de garimpeiros conseguiram tirar do papel as novas disposições relativas ao garimpo. $\mathrm{O}$ fosso entre a situação real e o quadro legal continua intransponível. O que se explica, em parte, por causa do fato de que a ênfase na exportação e nos grandes projetos ainda domina a visão governamental. Para complicar mais o problema, a preocupação ambiental, ao avançar entre os brasileiros, criou mais um foco de tensão.

Em Minas Gerais, os problemas sócio-ambientais associados ao garimpo ganharam relevo a partir de meados dos anos 1980. Em 1985, o Secretário de Estado de Ciência, Tecnologia e Meio Ambiente, Otávio Elísio Alves de Brito, organizou em Belo Horizonte reunião para discutir os problemas da mineração em Minas. Nesse evento, os garimpeiros de Teófilo Otoni aprovaram a tese de que o garimpo artesanal não seria fator de degradação ambiental, ao contrário do garimpo semi-mecanizado praticado em Diamantina e das grandes empresas de mineração. Ao lado dos impactos ambientais, a tensão das disputas por terras minerais também contribui para piorar a visão da opinião pública mineira sobre o garimpo. No mesmo ano, a imprensa de Belo Horizonte noticiou, estarrecida, o conflito entre garimpeiros de Datas e a Polícia Federal, no rio Paraúna. A briga era por causa da Hanna Corporation, empresa dona da área na qual trabalhavam muitos garimpeiros e que exigiu a retirada deles. A comunidade garimpeira, há muito instalada no local, resistiu. Conflito similar ocorreu dois anos depois, em Maria Nunes (Diamantina), com farta cobertura da imprensa. Sobre esses episódios, cita-se o depoimento de Antônio Fernandes, líder dos garimpeiros de Datas:

O Pe. Marcos, vigário de Datas, pediu que eu fosse lá, no Paraúna, dar uma ajuda para os garimpeiros. Nós fomos juntos, ocorreram algumas prisões, mas a comunidade conseguiu resistir e está lá até hoje. Depois teve outro conflito, em Maria Nunes, no Jequitinhonha, em 1987. Um grande minerador de Diamantina, dono de muitas bombas, Milton Queiroz, queria passar um trator sobre as casas dos moradores porque achava que, debaixo delas, havia muito diamante. Eu participei outra vez .

Em 1987, a Secretaria de Estado do Trabalho e Ação Social (Escritório Regional de Diamantina) organizou o I Encontro de Garimpeiros, em Coronel Murta. Nele, deliberou-se que os mineradores criariam associações. Mas somente os mineradores de Datas fundaram, naquele ano, sua entidade.

O ano de 1989 começou tenso. Em Goiás, a Justiça Estadual decretou a interdição dos garimpos de ouro do rio Vermelho. Doze mil garimpeiros foram impedidos de lavrar no estado vizinho ${ }^{10}$. Em Minas, depois de pressões fortes da AMDA (Associação Mineira de Defesa do Meio Ambiente), uma blitz da FEAM (Fundação Estadual do Meio Ambiente) lacrou 500 bombas de garimpo em Paracatu. Denúncias de operação predatória de bombas no rio Araçuaí levaram à instalação de CPI na Assembléia Legislativa. A CPI aumentou o movimento em favor da paralisação do garimpo no Alto Jequitinhonha. Mais uma vez, cita-se Antônio Fernandes:

Eu comecei a viajar para Belo Horizonte para defender o garimpo na Comissão de Meio Ambiente da 
Assembléia. Organizamos o II Encontro de Garimpeiros em Datas (...) com a presença do Deputado Nilmário Miranda e de técnicos da FEAM. Houve enfrentamento físico entre pessoas que achavam que o garimpo não fecharia nunca e o pessoal da FEAM. O Deputado Nilmário foi agredido. Os técnicos de Belo Horizonte voltaram inflamados para a capital e, no dia seguinte, só víamos helicópteros e camburões da Polícia chegar à região, lacrando as bombas.

Era 3 de agosto de 1989. O IBAMA interditou as atividades minerárias no Alto Jequitinhonha, baseado na Lei Federal 6.938/81 e no Decreto 88.351/83. As razões alegadas foram: a) o rio Jequitinhonha encontrava-se em estado crítico de poluição; b) a necessidade de garantir o abastecimento de água dos municípios a jusante do rio. Apanhados de surpresa, os garimpeiros de Diamantina tentaram sensibilizar as autoridades e o povo do município, concentrando-se no centro da cidade e montando rancho na Praça Correia Rabelo, diante da Prefeitura. Ficaram acampados ali de agosto a dezembro de 1989. Do acampamento partiam grupos de garimpeiros, diariamente, para fechar o comércio, as escolas e as repartições públicas. Os mais exaltados quiseram colocar explosivos na ponte de Mendanha, para interromper a estrada que dá acesso ao Vale do Jequitinhonha, mas foram detidos pelas lideranças moderadas do movimento . A Polícia Militar, apesar de alguns incidentes e do clima de apreensão na cidade, acompanhou a mobilização dos garimpeiros de longe. Enquanto isso, negociações foram entabuladas com as autoridades mineiras e os representantes de organizações ambientalistas Em setembro, surgiu a Cooperativa Regional Garimpeira de Diamantina, que se comprometeu fazer seus integrantes cumprirem as normas ambientais determinadas pela FEAM . Aos poucos, muitos garimpos voltaram a funcionar, após assinatura de termo de compromisso com a FEAM. Porém, não cessaram as ameaças de paralisação da atividade no Alto Jequitinhonha nos anos seguintes.

Em 1994, o Ministério Público de Diamantina formulou graves denúncias contra os garimpeiros: degradação ambiental, sonegação fiscal, exploração do trabalho infantil. A Polícia vistoriou áreas de garimpo e suspendeu temporariamente algumas frentes de lavra. Em 1995 foi desencadeada a "Operação Jequitinhonha" pela Polícia Federal, IEF (Instituto Estadual de Florestas), FEAM e IBAMA. Lavras no rio Jequitinhonha, entre Maria Nunes e Caçaratiba, foram embargadas. Em 1996, os órgãos ambientais paralisaram os garimpos do Serro e de Alvorada de Minas.

As lideranças garimpeiras enveredaram pelo caminho de pleitear tratamento legal, ambiental e fiscal diferenciado para o garimpo. O cerne de sua argumentação era a necessidade do governo reconhecer a distinção entre frentes de garimpagem e garimpo tradicional. A frente de garimpagem, predominante na Amazônia, configuraria garimpo circunstancial, assumido como alternativo de trabalho por pessoas não integradas ao mercado formal e nem às regiões onde aportam, que migraram predominantemente da agricultura de subsistência. O garimpo tradicional, ao contrário, aconteceria em comunidades bem assentadas, antigas, completamente adotadas pela unidade de vizinhança e que mantêm relações estáveis com a sociedade envolvente. Seria o garimpo de Minas e da Bahia, por exemplo. Para o garimpo tradicional, o governo deveria simplificar a burocracia e reduzir os impostos, elaborar exigências ambientais mais adequadas e factíveis, dar maior atenção à pesquisa e difusão de técnicas de baixo custo que melhorem a produtividade das lavras e minimizem os danos ambientais. Enfim, o garimpo não poderia ser tratado da mesma forma que a grande empresa de mineração.

Reivindicação que parece de bom senso. Entretanto, impossível de ser praticada nas condições da legislação mineraria e ambiental vigentes na década de 1990. O ponto relevante é que esta reivindicação encontrou guarida no interior do corpo técnico do DNPM, talvez por influência do viés produtivista que sempre caracterizou a atuação do órgão. Uma aliança tácita formou-se, então, entre os técnicos do DNPM e os garimpeiros de Diamantina nos fóruns de debate e nos conselhos deliberativos dos órgãos de política ambiental e minerária. Mas, para os integrantes da FEAM e do IBAMA, bem como para os membros das ONGs verdes, as exigências ambientais não poderiam ser relaxadas. A diferenciação solicitada pelos garimpeiros seria expediente de logro da legislação ambiental, por isso mesmo inaceitável. Por conseguinte, nos bastidores do governo, uma luta surda entre os órgãos com responsabilidade sobre o meio ambiente e os órgãos com responsabilidade sobre a produção mineral vem se travando desde os anos 1980-90.

Não bastasse a confusão da legislação, uma parte do governo empurra para um lado, e outra parte puxa para lado oposto. $\mathrm{O}$ entendimento é precário entre o setor mineral e o setor ambiental do governo. Algo que os projetos hidrelétricos lançados recentemente no país revelaram sobejamente. No garimpo da região de Diamantina, o mesmo ocorre, embora sem visibilidade na mídia.

A situação é agravada pelo processo de desmonte que, desde os anos 1990, atinge o DNPM e os órgãos ambientais IBAMA e FEAM. A crise fiscal do Estado e o avanço do neoliberalismo contribuíram para a desestruturação e o esvaziamento desses órgãos governamentais. A desorganização e a carência de profissionais dificultam que o DNPM planeje, fiscalize e controle o acesso e o aproveitamento dos recursos minerais. O mesmo acontece com o IBAMA e a FEAM, responsáveis primeiros pela resolução dos problemas dos impactos ambientais. Por outro lado, a arraigada tradição de setorização na administração brasileira

\footnotetext{
9 - Depoimento colhido pelo autor em 11 de outubro de 1996, na cidade de Diamantina. 1 fita cassete. 90 min.

${ }^{10}$ - Conforme a Revista Brasil Mineral, n. 73, dez. 1989, p. 8.
} 
coloca obstáculos de monta para o diálogo e a ação conjunta dos órgãos citados. A interlocução entre eles é episódica, e, muitas vezes, emerge publicamente com trocas de acusações de parte a parte.

Tanto as empresas quanto os garimpeiros, na sua maioria, procuram aproveitar a situação acima descrita para promover uma "corrida às jazidas", atropelando as normas minerárias, tributárias e ambientais. As empresas mineradoras continuaram a empregar a prática de lançar mão, em contratos feitos de boca, dos garimpeiros para tocar a exploração de áreas dentro de seus domínios minerais. Com isso, as empresas livramse dos passivos ambientais resultantes e obtêm minerais fora da vista do governo.

Talvez por isso o governo de Minas Gerais optou, no fim da década de 1990, por uma política de descentralização do controle ambiental do garimpo. A Deliberação Normativa n. 22/97, do COPAM (Conselho de Política Ambiental) de Minas Gerais, transferiu para os municípios conveniados a responsabilidade pelo licenciamento e fiscalização de atividades garimpeiras de pequeno porte.

Diamantina foi o primeiro município mineiro a firmar convênio com a FEAM, em outubro de 1998. O CODEMA (Conselho Municipal de Defesa do Meio Ambiente) de Diamantina passou a contar com um assessor ambiental, um assessor jurídico, uma secretária executiva, dois fiscais ambientais e um veículo, tudo bancado pela Prefeitura Municipal. O primeiro assessor ambiental do CODEMA de Diamantina foi um geólogo com longa folha de serviços prestados aos donos de garimpo da região. A Lei Municipal n. 2616, de abril de 2000, terceirizou a equipe técnica do órgão ambiental diamantinense. Os garimpeiros, como no tempo da Repartição dos Terrenos Diamantinos, lograram o controle do licenciamento e da fiscalização do garimpo no município. A raposa agora cuida do galinheiro, enquanto o granjeiro pousa para o público como moço afinado com a modernidade. Fato que alerta para os problemas que a proposta de descentralização da FEAM, realizada como simples transferência de responsabilidades para os municípios, poderá acarretar.

\section{CONSIDERAÇÕES FINAIS}

O breve exame dos marcos regulatórios da mineração na história do Brasil, voltado especificamente para o tratamento conferido ao garimpo e aos garimpeiros, evidencia os numerosos defeitos que caracterizam a legislação minerária e a atuação dos órgãos estatais de regulação, controle e fiscalização no decurso dos séculos.

A legislação do setor sempre foi confusa, preocupada quase exclusivamente com aspectos fiscais, excessivamente burocrática, cartorial mesmo. A atenção recaiu preferencialmente, desde o século XVIII, sobre o grande empreendimento minerador, orientado para a exportação dos recursos minerais. Por outro lado, ao mapear grosseiramente os atores presentes nas atividades mineradoras e seus interesses específicos, freqüentemente contraditórios, a legislação brasileira alimentou tensões e conflitos permanentes, que, por vezes, adquiriram intensidade elevada. Especialmente no que tange à violência entre empresas legais, grupos informais de mineradores e governo. Violência praticada de parte a parte.

No que se refere ao garimpo, a legislação brasileira e a ação governamental, ao optarem pela concentração gradual das atividades de mineração, jogaram os garimpeiros na situação de perene marginalização social e clandestinidade. No período colonial, como se viu, a garimpagem foi proibida e o garimpeiro transformado num criminoso. No Império e na República, o garimpo deixou de ser ilegal, embora continuasse marginalizado no âmbito da legislação minerária. Todavia, isso não reduziu a importância extraordinária do garimpo na produção de ouro, diamantes, gemas coradas, quartzo, mármore, pedras decorativas, etc. Nem impediu o convívio estreito, às vezes hostil, entre as empresas legais e os garimpeiros. As primeiras empregaram o concurso dos últimos para secundar seus serviços de lavras, promover evasão fiscal, reduzir custos de exploração e, recentemente, escapar da responsabilidade por passivos ambientais.

Quanto às relações entre o Estado e o garimpo, saltam aos olhos as recorrentes oscilações do humor oficial em relação aos garimpeiros. Nas fases de expansão da economia, geralmente o Estado estimulou a garimpagem. Porém, revertido o ciclo econômico, nas fases de recessão ou de desaceleração do crescimento da economia, o Estado empunhou política de repressão. Compreende-se porque o garimpeiro resiste ao contato e à colaboração com o Estado, fato que alimenta sua propensão a manter-se na informalidade e praticar sonegação.

O desafio brasileiro ainda é o mesmo do passado: elaborar e implementar política mineral racional, coerente, democrática, simultaneamente estimuladora da produção e promotora de inclusão social. Na medida em que a garimpagem, presente nas diversas partes do território nacional, possui dimensão econômica, social e cultural que não pode ser desprezada, esta política mineral exige enfoque mais abrangente. $\mathrm{O}$ garimpo, isto é, a pequena atividade mineradora, tem possibilidades de sobreviver por longo tempo ainda, no âmbito do regime das "reservas garimpeiras".

Mas isso exigirá esforço de ajustamento dos

\footnotetext{
11 - Conforme depoimento de José Arnaldo Jorge, primeiro advogado da Cooperativa Garimpeira de Diamantina, colhido pelo autor em 10 de outubro de 1996, em Diamantina. 1 fita cassete. 90 min.

12 - A Cooperativa, na verdade formada por donos de garimpos, fechou 1989 com 356 sócios. Em 1990, os sócios aumentaram para 639. No ano seguinte, havia 718 sócios e, em 1996, atingiu-se o pico: 890 sócios. Conforme Livros de Registros de Associados da COOPERGADI. Diamantina, MG.
} 
marcos legais e das ações regulatórias, a revisão dos encargos tributários e dos custos de formalização, o desenvolvimento de tecnologias apropriadas para esse tipo de empreendimento, a capacitação profissional dos garimpeiros, o estímulo e o apoio para a formação de cooperativas garimpeiras e a difusão da educação ambiental no seio das comunidades garimpeiras. Fazer isso, entretanto, equivale a realizar uma pequena "revolução copernicana" no modo como os policy makers brasileiros têm encarado o setor.

\section{REFERÊNCIAS BIBLIOGRÁFICAS}

ANASTASIA, Carla M. Junho. A geografia do crime: violência nas Minas Setecentistas. Belo Horizonte: Editora UFMG, 2005.

BRASIL. Ministério de Minas e Energia. Levantamento nacional dos garimpeiros. Brasília: DNPM, 1993. (Relatório Analítico)

CATHARINO, José Martins. Garimpo, garimpeiro, garimpagem Rio de Janeiro: Philobiblion; Salvador: Fundação Econômica Miguel Calmon, 1986.

FURTADO, Junia Ferreira. O Livro da Capa Verde: o Regimento Diamantino de 1771 e a vida no Distrito Diamantino no período da Real Extração. São Paulo: Annablume, 1996.

MARTINS, Marcos Lobato. Identidades sociais e ação coletiva: o caso dos garimpeiros da microrregião de Diamantina. Belo Horizonte: FAFICH/UFMG, 1997. (Dissertação de mestrado)

SANTOS, Joaquim Felício dos. Memórias do Distrito Diamantino. 4. ed. Belo Horizonte: Itatiaia, 1976.

SCLIAR, Cláudio. Potencial mineral do Alto Jequitinhonha. VI Seminário sobre a Economia Mineira. Belo Horizonte: CEDEPLAR/UFMG, 1992. p. 384-385. 